\title{
Perceived social support and diet quality among ethnic minority groups in Yunnan Province, Southwestern China: a cross- sectional study
}

Qiang Zhang ${ }^{1 \dagger}$, Yuan Ruan ${ }^{1 \dagger}$, Wenmin $\mathrm{Hu}^{1}$, Juanjuan $\mathrm{Li}^{1}$, Jiang Zhao ${ }^{1}$, Min Peng ${ }^{1}$, Rong Wan ${ }^{1}$, Xiangdong Min ${ }^{1}$, Shaomei He${ }^{2}$ and Zhitao Liu ${ }^{1 *}$

\begin{abstract}
Background: Social support is an important health determinant and may affect dietary behaviors. The purpose of this study was to examine the relations between perceived social support and the Chinese Diet Balance Index-16 (DBl-16) among ethnic minority groups in Southwest China.

Methods: This cross-sectional study was conducted between May 2019 and August 2020 among six ethnic minority groups native to Yunnan Province $(n=3564)$. Perceived social support from family, friends and significant others were measured with the Multi-dimensional Scale of Perceived Social Support (MSPSS). Dietary data were obtained using a 100-item Food Frequency Questionnaire (FFQ) and a lifestyle questionnaire. Lower Bound Score (LBS), Higher Bound Score (HBS) and Diet Quality Distance (DQD) which represent inadequate, excessive and unbalanced food intake respectively were calculated to measure the compliance with the recommendations of the Dietary Guidelines for Chinese 2016.

Results: One thousand four hundred ninety-six men and two thousand sixty-eight women were included. 51.2\% of the subjects had moderate or high levels of inadequate intake; $21.3 \%$ had moderate or high levels of excessive intake; and $74.0 \%$ had moderate or high levels of unbalanced dietary intake. With potential confounders adjusted, support from family was negatively associated with inadequate intake, while support from friends was positively associated with inadequate and excessive intake. No significant associations were found between perceived social support from significant others and diet quality indicators.
\end{abstract}

Conclusions: An unbalanced diet is common among adults of the ethnic minority groups in Yunnan Province, Southwest China. Social support should be taken into account in designing nutrition interventions rather than focusing solely on individuals.

Keywords: Ethnic minority, Diet balance index, Social support, China

\footnotetext{
* Correspondence: liuzhitao1977@126.com

${ }^{\dagger}$ Qiang Zhang and Yuan Ruan contributed equally to this work.

${ }^{1}$ Department of Nutrition and Food Hygiene, Yunnan Center for Disease Control and Prevention, Kunming 650022, China

Full list of author information is available at the end of the article
}

(c) The Author(s). 2021 Open Access This article is licensed under a Creative Commons Attribution 4.0 International License, which permits use, sharing, adaptation, distribution and reproduction in any medium or format, as long as you give appropriate credit to the original author(s) and the source, provide a link to the Creative Commons licence, and indicate if changes were made. The images or other third party material in this article are included in the article's Creative Commons licence, unless indicated otherwise in a credit line to the material. If material is not included in the article's Creative Commons licence and your intended use is not permitted by statutory regulation or exceeds the permitted use, you will need to obtain permission directly from the copyright holder. To view a copy of this licence, visit http://creativecommons.org/licenses/by/4.0/ The Creative Commons Public Domain Dedication waiver (http://creativecommons.org/publicdomain/zero/1.0/) applies to the data made available in this article, unless otherwise stated in a credit line to the data. 


\section{Background}

Unhealthy eating has become a serious public health problem worldwide $[1,2]$. It is estimated that 11 million deaths worldwide ( $22 \%$ of all deaths among adults) were attributable to dietary risk factors such as high intake of sodium, and low intake of whole grains and fruits [3]. Over the past decades, China has also experienced an accelerating nutrition transition characterized by unhealthy changes in dietary patterns and increasing prevalence of diet-related diseases [4, 5]. Nearly half of Chinese adults are facing the problem of double burden of malnutrition, which refers to the coexistence of micronutrient deficiencies along with overweight and obesity within individuals [6].

To promote healthy eating behaviors among the public, some countries have developed dietary guidelines based on scientific evidence and local dietary habits [7, 8]. Dietary indexes such as Healthy Eating Index (HEI) for Americans and Diet Balance Index (DBI) for Chinese, have also been constructed to measure how well individual diets meet recommendations of the guidelines $[9,10]$. In addition to dietary assessment, these priori indexes are also used to examine associations between diet quality and health outcomes [11, 12]. Notably, data from the 2010-2012 China Nutrition and Heath Surveillance showed that $73.6 \%$ adults were at moderate or high levels of inadequate food intake, while $27.9 \%$ were at moderate or high levels of excessive food intake [13]. What's more, diet imbalance is more likely to be found among people living in rural areas, with lower education level and household income [12]. In recent years, social and interpersonal influences on dietary behaviors have received increasing attention. For example, a study in Canada shows that social deprivation (an indicator reflects deprivation of social networks, from family to community) is associated with lower diet quality [14]. In contrast, another study from Switzerland reported that women who dined more often with healthy eaters were on a higher diet quality and a lower body mass index (BMI) [15]. These findings suggest that social networks may have a shared perception of healthy eating, which would influence individual's dietary practices. Thus, individual's social relationships would be an important consideration for healthy eating promotion.

Social support is the emotional, instrumental and informational aid exchanged through social relationships and interpersonal transactions, which can be measured as perceived support or received support [16]. Perceived social support is the mostly measured index for its ease of measurement and strong associations with health outcomes $[17,18]$. Although positive and causal relations between social support and health have been well documented, the influence of social support on some key health-related behaviors like diet are still understudied, especially in adults. For single food intakes of individuals, social support often appears a protective effect. For example, two studies from the United States show that social support was correlated with high consumptions of fruits and vegetables, or low consumptions of sugar and processed meat $[19,20]$. In contrast, the relations between social support and overall diet quality remain controversial. In one study, social support was positively associated with HEI-2010 among middle-aged and older US men; however, such association was not statistically significant among American minority youths [21, 22]. Moreover, sources of social support may have different effects on eating behaviors. For instance, fruit and vegetable consumption were positively associated with family support, but not with friend or pastor support among African-Americans [23]. In addition, effects of social support on dietary behaviors may also differ in gender, age and ethnicity [24, 25]. Thus, although social support being perceived as one of the best strategies to promote health, the associations of between social support and dietary behaviors need to be further examined in certain contexts.

Yunnan Province is a less developed and multi-ethnic province in Southwest China. Benefited from the National Poverty Alleviation and Development Program, the local economy has been growing at a high speed in the past decades, especially in the ethnic regions. Therefore, we hypothesize that unbalanced dietary consumptions would have emerged among the ethnic minority groups and social support may have a role in this process. In his study, we examined the associations between sources of perceived social support and DBI-16 among adults of six ethnic minority groups in Yunnan Province. The purpose of the study was to evaluate dietary intakes of the ethnic groups and further understand the influential factors.

\section{Methods \\ Study design}

Data for this study were from the 2019-2020 nutrition and health survey of ethnic minorities native to Yunnan Province. Adults of six ethnic minority groups with a total population less than 150,000 were included, which were A Chang, Bu Lang, De Ang, Jing Po, Ji Nuo and Pu $\mathrm{Mi}$ [26]. Most of these groups live in certain mountain towns. Thus, a multistage sampling method was used to recruit participants. First, six towns with the largest population of A Chang, Bu Lang, De Ang, Jing Po, Ji Nuo or $\mathrm{Pu} \mathrm{Mi}$ ethnicity were chosen as the study sites. Second, two villages were selected with the Probability Proportional to Size sampling method (number of households). Then, 150 households were randomly selected based on local household registration information. Finally, all adults at home of the sampled households 
were invited to join the survey, except those who were on a prescribed diet or who had serious illnesses.

The sample size was determined from careful power analysis considering the following four factors: a prevalence of hypertension of $15 \%$ (the most prevalent nutrition-related disease in the population), a desired precision of 3\%, a type I error of 0.05 and the population of each ethnic minority group. The minimum sample size per minority group ranged from 545 to 570 . We aimed at recruiting 600 participants per site, considering potential of $10 \%$ non-response. Data were collected through a face-to-face interview by trained local health workers. Altogether, 3660 participants aged 18 years and over completed the survey, with a response rate of $89.0 \%$. Ninety-six participants were excluded because of missing key information (39 subjects), or implausible energy intake $(<800 \mathrm{kcal}(\mathrm{kcal})$ per day or $>6000 \mathrm{kcal}$ for men and $<600 \mathrm{kcal}$ or $>4000 \mathrm{kcal}$ for women, $57 \mathrm{sub}$ jects) [27]. The final analysis has been conducted on 3564 participants (Fig. 1).

\section{Dietary data collection}

Dietary intakes over the past year were assessed using a 100-itemFood Frequency Questionnaire (FFQ). These items include cereals ( 9 items), beans ( 7 items), fresh vegetables (8 items), salt vegetables ( 2 items), mushrooms ( 2 items), algae ( 2 items), fruits (7 items), dairy (7 items), meat (14 items), fish (12 items), eggs (3 items), snacks (18 items) and beverages (9 items), which were commonly consumed by the Chinese population. The FFQ was validated and proved to be a useful tool for the collection individual dietary intake in face-to-face interviews [28, 29]. Based on the frequency and amount of food consumption reported by individual participants, daily intake of each food item was calculated.

In addition, data of alcohol consumption was derived from the lifestyle questionnaire of the survey. Participants were inquired the drinking frequency and quantity of alcoholic beverages (such as high alcohol liquor, low alcohol liquor, wine, beer and etc.) in the past 12 months. Alcohol in each alcoholic beverage was converted following DBI-16 criteria and then summed to calculate average alcohol consumption per day Daily energy intake for individuals was calculated using the dietary data in conjunction with the China Food Composition Table [30]. Moreover, daily intakes of the food items were also summed by food group classifications correspond with the DBI-16 criteria for further analysis [31].

\section{Dietary balance Index-16}

DBI-16 is devised to assess diet quality in Chinese population. It comprises eight components from "the Chinese Dietary Guidelines 2016" including: (1)

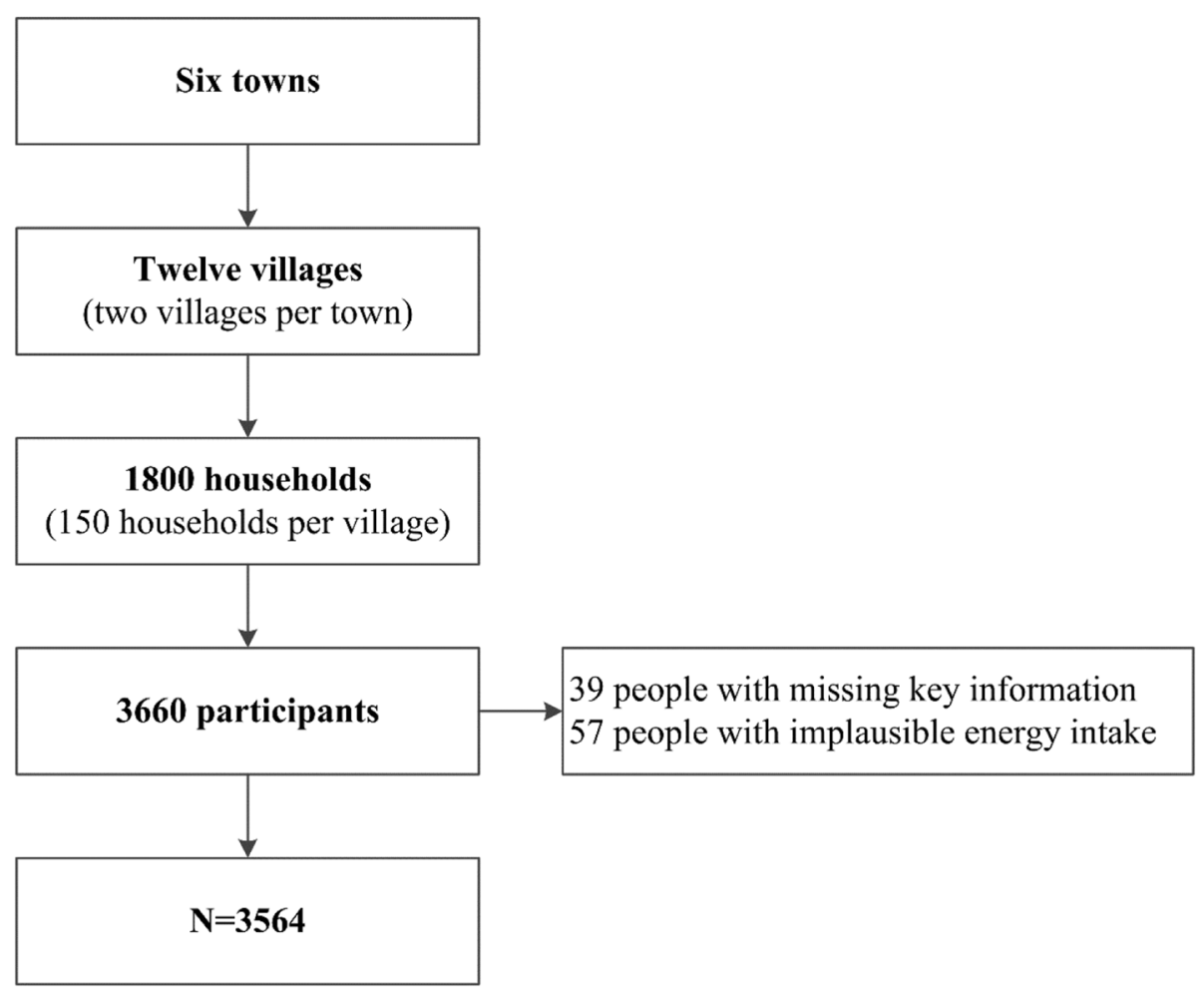

Fig. 1 Flowchart of the study population 
Cereals; (2) Vegetables and fruits; (3) Milk and dairy products, soybean and soybean products; (4) Animal foods; (5) empty energy foods; (6) Condiments; (7) Diet variety; (8) Drinking water. A score of 0 for each DBI-16 component means meeting the recommended intake amounts. Positive scores (range 0-12) were used to assess excessive intake levels of empty energy foods and condiments, which the guidelines recommended consuming in a "limited" amount. Similarly, negative scores (range - 12,0) were used to assess inadequate intake levels of vegetables and fruits, dairy and soybeans, dietary diversity and drinking water, which the guidelines recommended that people should "eat plenty" or "enjoy". Moreover, both positive and negative scores were used to evaluate the intake levels of cereals $(-12,12)$ and animal food $(-12,8)$, which the guidelines recommend consuming in an "appropriate" amount. In considering the difference of nutrient requirements in energy consumption, the scoring of each component is based on eleven energy intake levels, respectively. The intakes of 12 identified food groups are used to assess the diet variety component of DBI-16. These food groups were (1) rice and products; (2) wheat and products; (3) corn, coarse grains and products, starchy roots and products; (4) darkcolored vegetables; (5) light-colored vegetables; (6) fruits; (7) soybean and products; (8) milk and dairy products; (9) red meat and products; (10) poultry and game; (11) eggs; (12) fish and shellfish. A score of 0 is assigned to a food group if the intakes reach or exceed the lowest recommended intake $(5 \mathrm{~g}$ for soybean and $25 \mathrm{~g}$ for other 11 food groups). Else, a score of -1 is assigned. The score of diet variety component ranges from -12 to $0[24,29,30]$. Scoring details of DBI-16 can be found in Table S1.

Based on the scores for each DBI-16 component, three indicators of diet quality are calculated. Higher Bound Score (HBS), the indicator for excessive intake, is calculated by adding all the positive scores. Lower Bound Score (LBS), the indicator for inadequate intake, is computed by adding all the negative scores. Diet Quality Distance (DQD), indicator of unbalanced food intake, is calculated by the absolute values of both positive and negative scores. For data on water consumption was not available in the survey, the component of 'drinking water' was not assessed in this study. Therefore, the range of HBS, LBS and DQD were: 0 to 44,0 to 60 and 0 to 84 , respectively. Each indicator is further divided into five levels to reflect diet quality for simplicity. They are "no problem" (a score of 0), "almost no problem" (less than 20\% of the total score), "low level" (between 20 and $40 \%$ of the total score), "moderate level" (between 40 and
$60 \%$ of the total score) and "high level" (greater than $60 \%$ of the total score) $[24,29,30]$.

\section{Measurements of perceived social support}

Perceived social support was measured by using the Multi-dimensional Scale of Perceived Social Support (MSPSS). This scale consists of 12 items with 4 items measuring family support, 4 items measuring friend support and 4 items measuring significant others support. Responses for each item were ranked on a five-point Likert scale. Total scores for family, friend and significant others support were respectively calculated and used in following analysis. MSPSS is one of the most extensively used instruments to assess social support and the reliability and validity have verified in different groups. Correlation analysis showed that the alpha coefficient of the scale was 0.95 in this study. In this study, confirmatory factor analysis showed a robust threefactor structure of the scale and the Cronbach's alpha coefficients of three factors were $0.94,0.91$ and 0.95 , respectively. In addition, the alpha coefficients for A Chang, Bu Lang, De Ang, Jing Po, Ji Nuo and Pi Mi ethnicity ranged from 0.93 to 0.95 . The MSPSS can be found in Table S2.

\section{Covariates}

Sociodemographic characteristics of the participants were incorporated in the analyses as potential confounders, including age, sex, ethnicity, education, income, and Engel's coefficient. Age was divided into five groups $(18-34,35-44,45-59$ and $\geq 60$ years) in the descriptive statistics, while treated as a continuous variable in the logistic regression analyses. Education was classified as three levels (primary school and below, middle school, high school and above). Income was measured with household income per capita in the last 12 months and categorized into four categories $(<5000$ Yuan, 5000-9999 Yuan and $\geq 10,000$ Yuan). Engel's coefficient was classified as four levels $(\geq 0.50$ subsistence level; $0.40-0.49$ well level; $0.30-0.39$ relatively rich; $<0.30$ rich) [32].

\section{Data analysis}

Categorical variables (e.g., sex, and age groups) are presented as percentage, while numeric variables which normally distributed (e.g., perceived social support scores) were presented as mean and standard deviation (SD) and which not normally distributed were presented as median (e.g., DBI-16 component scores and indicators). Kruskal-Wallis one-way analysis was used to examine the associations between sociodemographic characteristics and DBI-16 indicators. Logistics regression analysis was used to estimate the associations between perceived social support scores and diet quality 
with potential confounders adjustment. All statistical analyses were performed with SAS Software 9.4 (SAS Institute, Cary, North Carolina, USA). Statistical significance was set at $P<0.05$.

\section{Results}

Table 1 shows the characteristics of the study population. A total of 3564 ethnic adults were included in the final analysis, comprising 1496 men (42\%) and 2068 women (58\%). Proportions of subjects aged 18-34, 3544, 45-59, 60 years and older were 20.2, 21.7, 35.6 and $22.5 \%$, respectively. Each of the six ethnic minority groups approximately accounted for $16 \%$ of the sample. Most of the participants were farmers and over one third

Table 1 Characteristics of the participants

\begin{tabular}{|c|c|c|}
\hline & $\mathrm{N}$ & $\%$ \\
\hline \multicolumn{3}{|l|}{$\operatorname{Sex}(\%)$} \\
\hline Men & 1496 & 42.0 \\
\hline Women & 2068 & 58.0 \\
\hline \multicolumn{3}{|l|}{ Age in years (\%) } \\
\hline $18-34$ & 721 & 20.2 \\
\hline $35-44$ & 774 & 21.7 \\
\hline $45-59$ & 1268 & 35.6 \\
\hline$\geq 60$ & 801 & 22.5 \\
\hline \multicolumn{3}{|l|}{ Ethnicity (\%) } \\
\hline A Chang & 592 & 16.6 \\
\hline Bu Lang & 604 & 16.9 \\
\hline De Ang & 611 & 17.1 \\
\hline Jing Po & 606 & 17.0 \\
\hline Ji Nuo & 598 & 16.8 \\
\hline Pu Mi & 553 & 15.5 \\
\hline \multicolumn{3}{|l|}{ Education (\%) } \\
\hline Primary school and below & 1248 & 35.0 \\
\hline Middle school & 1423 & 39.9 \\
\hline High school and above & 893 & 25.1 \\
\hline \multicolumn{3}{|l|}{ Occupations (\%) } \\
\hline Farmer & 3364 & 94.4 \\
\hline Others & 200 & 5.6 \\
\hline \multicolumn{3}{|c|}{ Household income per capita (\%) } \\
\hline$<5000$ Yuan/year & 870 & 24.4 \\
\hline 5000-9999 Yuan/year & 1367 & 38.4 \\
\hline$\geq 10,000$ Yuan/year & 1327 & 37.2 \\
\hline \multicolumn{3}{|l|}{ Engel's coefficient (\%) } \\
\hline$\geq 0.50$ & 867 & 24.3 \\
\hline $0.40-0.49$ & 684 & 19.2 \\
\hline $0.30-0.39$ & 1087 & 30.5 \\
\hline$<0.30$ & 926 & 26.0 \\
\hline
\end{tabular}

only had primary school or no formal education. Nearly one fourth of the adults had a household income less than 5000 Yuan per year.

Table 2 presents the scores for DBI-16 components and the percentage of people with each score. Over intakes of cereals, meat and oil were common, with the score for about 80 to $90 \%$ participants being in the positive range. In contrast, under intakes of dairy, fruits and fish were also common, with over $90 \%$ of the ethnic adults having a negative score. Diet variety was very poor in the population, with almost all of them (99.9\%) in the negative range.

The distribution of DBI-16 indicators is presented in Table 3. The LBS indicated that $51.2 \%$ of the participants had moderate or high levels of inadequate food intake, respectively. The distribution of HBS indicated that $21.3 \%$ of people had a moderate or excessive food intake. According to the distribution of the DQD, an indicator used to evaluate the overall unbalance in dietary intake levels, $74 \%$ of the ethnic adults had moderate or high levels of unbalanced food intake.

Table 4 shows the median scores for LBS, HBS and DQD by sociodemographic characteristics of the participants. Results of Kruskal-Wallis test indicated that women and people who were younger, had higher education or income were less likely to have inadequate, excessive and unbalanced dietary intakes.

Associations between moderate or high levels of inadequate and excessive food intake and perceived social support are shown in Table 5. Logistic regression models with potential confounders adjustment showed that support from family were negatively associated with inadequate food intake, while support from friends were positively associated with both inadequate and excessive food intake. No significant associations were found between support from significant others and DBI-16 indicators.

Table 6 show the correlation coefficients between DBI-16 component scores and perceived social support. Support from family were positively associated with intakes of fruits, dairy, fish, egg and diet variety, while negatively associated with vegetable and meat consumption. Support from friends were positively associated with intakes of dairy, beans, fish, egg, sugar and diet variety, while negatively associated with cereals, vegetable and meat consumptions. Support from significant others were positively associated with intakes of dairy, beans, fish, egg, sugar and diet variety, while negatively associated with cereals, vegetable and meat consumptions.

\section{Discussions}

The cross-sectional study examined the associations between diet quality and perceived social support among adults of six ethnic minority groups in Yunnan Province, 
Table 2 DBI-16 component scores and percentage of the participants with each score

\begin{tabular}{|c|c|c|c|c|c|c|c|c|c|c|c|c|c|}
\hline \multirow[t]{2}{*}{ Scores } & \multirow[t]{2}{*}{ Cereals } & \multicolumn{2}{|c|}{ Vegetables \& Fruits } & \multicolumn{2}{|c|}{ Dairy \& Beans } & \multicolumn{3}{|c|}{ Animal source foods } & \multicolumn{2}{|c|}{ Oil \& alcohol } & \multicolumn{2}{|c|}{ Sugar\& salt } & \multirow{2}{*}{$\begin{array}{l}\text { Diet } \\
\text { variety }\end{array}$} \\
\hline & & Vegetables & Fruits & Dairy & Beans & Meat & Fish & Eggs & Oil & Alcohol & Sugar & Salt & \\
\hline$-12 \sim-11$ & & & & & & & & & & & & & 0.2 \\
\hline$-10 \sim-9$ & & & & & & & & & & & & & 3.6 \\
\hline$-8 \sim-7$ & 0.1 & & & & & & & & & & & & 26.5 \\
\hline$-6 \sim-5$ & 0.9 & 13.2 & 35.3 & 84.4 & 19.0 & & & & & & & & 42.4 \\
\hline$-4 \sim-3$ & 1.4 & 47.6 & 44.0 & 10.7 & 32.3 & 1.4 & 75.4 & 33.1 & & & & & 20.6 \\
\hline$-2 \sim-1$ & 2.9 & 25.8 & 11.7 & 3.2 & 17.0 & 7.8 & 15.3 & 35.4 & & & & & 6.7 \\
\hline 0 & 6.2 & 13.4 & 8.9 & 1.7 & 31.7 & 9.9 & 9.3 & 14.7 & 15.8 & 86.7 & 99.8 & 23.8 & 0.1 \\
\hline $1 \sim 2$ & 7.7 & & & & & 14.7 & & 7.6 & 32.6 & 7.4 & 0.1 & 56.5 & \\
\hline $3 \sim 4$ & 11.9 & & & & & 66.2 & & 9.2 & 23.1 & 2.1 & 0.1 & 15.7 & \\
\hline $5 \sim 6$ & 14.4 & & & & & & & & 28.5 & 3.8 & 0 & 4.0 & \\
\hline $7 \sim 8$ & 14.6 & & & & & & & & & & & & \\
\hline $9 \sim 10$ & 9.7 & & & & & & & & & & & & \\
\hline $11 \sim 12$ & 30.2 & & & & & & & & & & & & \\
\hline Median & 7 & -3 & -4 & -5 & -3 & 4 & -4 & -2 & 3 & 0 & 0 & 1 & -6 \\
\hline
\end{tabular}

Southwest China.. Dietary assessment with DBI-16 indicated that dietary imbalance is common among the population, especially among men and those who are older, had lower education or income levels. Notably, support from family, friends and significant others showed different effects on healthy eating. To our best knowledge, this was the first study to explore interpersonal factors of dietary behaviors among ethnic minorities in less developed areas of China.

There are 15 ethnic minority groups native to Yunnan Province. Historically, these groups live in remote, poor areas. A study conducted in Yunnan among preschoolaged children 10 years ago showed that the prevalence of stunting, underweight and wasting were significantly higher in ethnic minority groups than in Han ethnicity [33]. Benefited from the poverty alleviation work in recent years, these areas have achieved impressive economic developments. In the former case, changes in lifestyle and diet often come with rapid economic developments [34, 35]. A longitudinal study in China showed that between 1995 and 2014 stunting, thinness continued to reduce in school-aged children and adolescents while the prevalence of obesity markedly increased [36]. In this study, Engel's coefficient is 0.4, suggesting that living standard of the ethnic minority groups is just at a crucial stage of nutrition transition. Besides, most of the ethnic adults are low educated and have poor health awareness, which would make them difficult to develop or keep a healthy dietary habit in the nutrition transition. A recent study showed that although the prevalence of non-communicable chronic diseases in adults of $\mathrm{Nu}$ ethnicity was still lower than in Han Chinese, excessive intakes of meat and cereals were more prevalent in the former [37, 38]. For developing and implementing targeted intervention programs, it is of significance to evaluate diet quality and influential factors of the population.

Our findings indicate that $51.2 \%$ of the ethnic minority groups had moderate or high levels of inadequate food intake; $23.3 \%$ had moderate or high levels of excessive food intake; and $74.0 \%$ had moderate or high levels of unbalanced food intake. In contrast to a recent Chinese national representative study, diet quality of the study population already exceeded than the rural residents but was still inferior to the urban residents (LBS: 56.991.0\%; HBS: 22.3-33.7\%; DQD: 58.6-89.1\%) [31]. Diet quality is usually better among urban residents due to higher income and more diversified food supply [39]. This study reflects the effect of rapid urbanization on dietary patterns among the population. Our results that

Table 3 Distribution of DBI-16 indicators among the participants

\begin{tabular}{llllll}
\hline Indicators & Range & \multicolumn{3}{l}{ Distribution of Diet Quality (\%) } \\
\cline { 2 - 6 } & & Almost no problem & Low level & Moderate level & High level \\
\hline LBS & $0-44$ & $0-8(3.8)$ & $9-17(45.0)$ & $18-26(50.0)$ & $26-44(1.2)$ \\
HBS & $0-60$ & $0-11(9.5)$ & $12-23(69.2)$ & $24-35(21.1)$ & $36-60(0.2)$ \\
DQD & $0-84$ & $0-16(0.8)$ & $17-33(25.2)$ & $34-50(66.5)$ & $51-84(7.5)$ \\
\hline
\end{tabular}


Table 4 Predictors of DBI-16 indicators

\begin{tabular}{|c|c|c|c|c|c|c|}
\hline & LBS & $p$ & HBS & $p$ & DQD & $p$ \\
\hline \multicolumn{7}{|l|}{ Sex } \\
\hline Men & 20 & & 16 & & 40 & \\
\hline Women & 19 & $<0.01$ & 15 & $<0.01$ & 40 & 0.04 \\
\hline \multicolumn{7}{|l|}{ Age in years } \\
\hline $18-34$ & 18 & & 15 & & 38 & \\
\hline $35-44$ & 20 & & 15 & & 40 & \\
\hline $45-59$ & 20 & & 15 & & 41 & \\
\hline$\geq 60$ & 21 & $<0.01$ & 16 & $<0.01$ & 42 & $<0.01$ \\
\hline \multicolumn{7}{|l|}{ Education } \\
\hline Primary school and below & 20 & & 16 & & 41 & \\
\hline Middle school & 20 & & 16 & & 41 & \\
\hline High school and above & 19 & $<0.01$ & 15 & $<0.01$ & 38 & $<0.01$ \\
\hline \multicolumn{7}{|l|}{ Annual Income (Yuan) } \\
\hline$<5000$ & 20 & & 16 & & 42 & \\
\hline 5000-9999 & 20 & & 16 & & 41 & \\
\hline$\geq 10,000$ & 19 & $<0.01$ & 15 & $<0.01$ & 39 & $<0.01$ \\
\hline
\end{tabular}

there were socioeconomic disparities in diet quality are consistent with previous studies, highlight the necessity of paying more attention on people with low socioeconomic status $[10,40]$. One interesting finding of our study is that only $10 \%$ of the study population consumed adequate vegetables and fruits, which is lower than people in Shanghai (about 20\%) [39]. But actually, vegetables and fruits are fairly cheap and widely available in the ethnic areas. In contrast, over $80 \%$ of the subjects had excessive intake of meat, which was even higher than urban residents in Shanghai (about 60\%) [39]. These findings suggest that the ethnic minority groups would not have formed a correct perception of what constitutes a healthy diet. Thus, more research is required to understand the influential factors in addition to economic development and personal income.

In the literature, social support has been proposed as a social psychological mechanism that social ties affect bodily and emotional well-being [41]. People can obtain both normative and behavioral guidance through comparisons with others, for example, norms about healthy eating. Besides, facts or recommendations from others may enable subsequent behavioral changes that make everyday tasks more efficient, economical or successful. Thus, social support is recognized as a promising strategy to promote health and has been used in clinical and adolescent nutrition interventions [42, 43]. In this study, social support from different sources showed different effects on healthy eating. Family support had a protective effect for inadequate food intake, whereas the support from friends was a risk factor for both inadequate and excessive food intake. And no significant associations were found between diet quality and the support from significant others. These results suggest that the influences of social relationships on dietary behaviors in the ethnic population are mainly from family and friends. In terms of individual food intakes, effect directions of the three sources of social support are generally consistent. This finding may imply that the perception of healthy eating across the three types of people are homogenous. In addition, the effects of perceived social support on individual food consumption are not completely consistent with recommendations of the Dietary Guidelines. For example, social support is positively associated with diet variety and dairy consumption but also negatively associated with vegetable intakes. This result may reflect the fact that nutrition knowledge among the ethnic minority groups are fragmental and inaccurate. In the current "Healthy China Action", supportive environment construction (including infrastructure and relationships) is particularly emphasized [44, 45]. Thus, future studies may wish to focus on how to incorporate social support in healthy eating promotions of the public.

There are several limitations to this study. First, the cross-sectional design of the study restricts casual inference between dietary intakes and perceived social support. Second, although a FFQ could prevent seasonal variations in dietary intakes, the self-report food intake within a year might be subject to recall bias. Third, although socioeconomic factors are adjusted in the regression models, potential factors at contextual levels for both diets and social support are not fully considered, for example cultural differences in the ethnic minority

Table 5 Associations between moderate or high levels of inadequate/excessive food intake and social support

\begin{tabular}{|c|c|c|c|c|}
\hline \multirow{2}{*}{$\begin{array}{l}\text { Dependent } \\
\text { variables }\end{array}$} & & \multicolumn{3}{|c|}{ Perceived social support from } \\
\hline & & Family & Friends & Significant others \\
\hline \multirow[t]{2}{*}{ LBS } & Model 1 & $-0.02(-0.05,0.01)$ & $0.04(0.01,0.07)$ & $0.02(-0.01,0.05)$ \\
\hline & Model 2 & $-0.04(-0.06,-0.01)$ & $0.04(0.01,0.08)$ & $0.01(-0.02,0.04)$ \\
\hline \multirow[t]{2}{*}{ HBS } & Model 1 & $-0.01(-0.05,0.02)$ & $0.06(0.02,0.10)$ & $0.01(-0.03,0.05)$ \\
\hline & Model 2 & $-0.02(-0.05,0.02)$ & $0.05(0.01,0.10)$ & $0.02(-0.02,0.06)$ \\
\hline
\end{tabular}

Model 1: Crude model; Model 2: adjustment for age, sex, education, income, ethnicity and Engel's coefficient. Values in bold are statistically significant at the 0.05 level 
Table 6 Correlations between DBI-16 component scores and perceived social support

\begin{tabular}{lllll}
\hline DBI & Score & \multicolumn{3}{l}{ Social support from } \\
\cline { 3 - 5 } & range & Family & Friends & Others \\
\hline Cereals & $-12,12$ & -0.01 & $-\mathbf{0 . 1 0}$ & $-\mathbf{0 . 0 7}$ \\
Vegetables & $-6,0$ & $-\mathbf{0 . 1 3}$ & $-\mathbf{0 . 1 9}$ & $-\mathbf{0 . 1 9}$ \\
Fruits & $-6,0$ & $\mathbf{0 . 1 0}$ & -0.01 & 0.02 \\
Dairy & $-6,0$ & $\mathbf{0 . 1 0}$ & $\mathbf{0 . 1 3}$ & $\mathbf{0 . 1 4}$ \\
Beans & $-6,0$ & 0.03 & $\mathbf{0 . 1 5}$ & $\mathbf{0 . 1 4}$ \\
Meat & $-4,4$ & $-\mathbf{0 . 1 2}$ & $-\mathbf{0 . 1 8}$ & $-\mathbf{0 . 0 4}$ \\
Fish & $-4,0$ & $\mathbf{0 . 0 9}$ & $\mathbf{0 . 1 5}$ & $\mathbf{0 . 1 6}$ \\
Eggs & $-4,4$ & $\mathbf{0 . 0 5}$ & $\mathbf{0 . 1 3}$ & $\mathbf{0 . 1 5}$ \\
Oil & 0,6 & -0.01 & $\mathbf{0 . 0 5}$ & 0.03 \\
Alcohol & 0,6 & 0.02 & 0.01 & 0.01 \\
Sugar & 0,6 & 0.02 & $\mathbf{0 . 0 5}$ & $\mathbf{0 0 . 7}$ \\
Salt & 0,6 & 0.01 & -0.01 & 0.01 \\
Diet variety & $-12,0$ & $\mathbf{0 . 0 7}$ & $\mathbf{0 . 1 6}$ & $\mathbf{0 . 1 7}$ \\
\hline Valy & &
\end{tabular}

Values in bold are statistically significant at the 0.05 level

groups. Last but not least, we only calculated the individual intake of condiments and sugar based on consumption at home and exclude the intakes outside the home. Thus, the consumption of oil, salt and sugar might be underestimated.

\section{Conclusions}

In conclusion, unbalanced dietary consumption is common among the ethnic minority groups in Yunnan Province. Perception of support from family, friends and significant others has an effect on overall diet quality, and should be taken into account when designing and implementing intervention programs.

\section{Abbreviations}

DBI-16: Diet Balance Index-16; LBS: Lower Bound Score; HBS: Higher Bound Score; DQD: Diet Quality Distance; MSPSS: Multi-dimensional Scale of Perceived Social Support

\section{Supplementary Information}

The online version contains supplementary material available at https://doi. org/10.1186/s12889-021-11787-5

Additional file 1: Table S1. Components of DBI-16.

Additional file 2: Table S2. The Multi-dimensional Scale of Perceived Social Support (MSPSS).

\section{Acknowledgements}

The authors would like to thank the participants, and also to the doctors and nurses from local centers for disease control and prevention, and hospitals.

\section{Authors' contributions}

QZ and LZ conceived the study and revised the manuscript. YR and JZ performed data analysis and drafted the manuscript. WH, JL, MP, SH and RW contributed to data collection. XM reviewed the manuscript. All authors read and approved the final manuscript.

\section{Funding}

This study was funded by the High-level Health Talents Project of Yunnan Province ( $\mathrm{H}-2018046$ to QZ) and the Health Commission of Yunnan Province (2018NS-0230 to ZL). The funders had no role in study design, data collection and analysis, decision to publish, or preparation of the manuscript.

\section{Availability of data and materials}

The data used in this study are available from the corresponding author on reasonable request.

\section{Declarations}

Ethics approval and consent to participate

The study was approved by the Institutional Review Board at Yunnan Center for Disease Control and Prevention (2019-01). All protocols are carried out in accordance with the principles of the Declaration of Helsinki. Signed informed consent was obtained from all the participants.

Consent for publication

Not applicable.

\section{Competing interests}

The authors declare that they have no competing interests.

\section{Author details}

${ }^{1}$ Department of Nutrition and Food Hygiene, Yunnan Center for Disease Control and Prevention, Kunming 650022, China. ${ }^{2}$ Department of Chronic Disease Prevention, Lanping County Center for Disease Control and Prevention, Lanping 671400, China.

Received: 22 March 2021 Accepted: 29 August 2021

Published online: 23 September 2021

\section{References}

1. White M, Aguirre E, Finegood DT, Holmes C, Sacks G, Smith R. What role should the commercial food system play in promoting health through better diet? BMJ. 2020:368:1-12. https://doi.org/10.1136/bmj.m545.

2. Kuehn B. Improving nutrition to save lives. JAMA. 2019;322(15):1441. https:// doi.org/10.1001/jama.2019.16414.

3. Collaborators GBDD. Health effects of dietary risks in 195 countries, 19902017: a systematic analysis for the global burden of disease study 2017. Lancet. 2019;393(10184):1958-72.

4. Li M, Shi Z. Dietary pattern during 1991-2011 and its association with cardio metabolic risks in Chinese adults: the China health and nutrition survey. Nutrients. 2017;9(11):1-13. https://doi.org/10.3390/nu9111218.

5. Zhen S, Ma Y, Zhao Z, Yang X, Wen D. Dietary pattern is associated with obesity in Chinese children and adolescents: data from China health and nutrition survey (CHNS). Nutr J. 2018;17(1):1-9. https://doi.org/10.1186/s1293 7-018-0372-8.

6. Huang $Q$, Wang $L$, Jiang $H$, Wang $H$, Zhang $B$, Zhang J, et al. Intra-individual double burden of malnutrition among adults in China: evidence from the China health and nutrition survey 2015. Nutrients. 2020;12(9):1-13.

7. Hu FB, Neuhouser ML, Perez-Escamilla R, Martinez-Gonzalez MA, Willett WC. US Dietary Guidelines. Ann Intern Med. 2016;165(8):604-5. https://doi.org/10. 7326/L16-0170.

8. Yang $Y X$, Wang $X L$, Leong $P M$, Zhang $H M$, Yang $X G$, Kong $L Z$, et al. New Chinese dietary guidelines: healthy eating patterns and food-based dietary recommendations. Asia Pac J Clin Nutr. 2018;27(4):908-13. https://doi.org/1 0.6133/apjen.072018.03.

9. Krebs-Smith SM, Pannucci TE, Subar AF, Kirkpatrick SI, Lerman JL, Tooze JA, et al. Update of the healthy eating index: HEI-2015. J Acad Nutr Diet. 2018; 118(9):1591-602. https://doi.org/10.1016/j.jand.2018.05.021.

10. He D, Qiao Y, Xiong S, Liu S, Ke C, Shen Y. Association between dietary quality and prediabetes based on the diet balance index. Sci Rep. 2020; 10(1):1-7. https://doi.org/10.1038/s41598-020-60153-9.

11. Tangney CC, Kwasny MJ, Li H, Wilson RS, Evans DA, Morris MC. Adherence to a Mediterranean-type dietary pattern and cognitive decline in a community population. Am J Clin Nutr. 2011;93(3):601-7. https://doi.org/1 0.3945/ajen.110.007369.

12. Zhang Q, Qin G, Liu Z, Li Z, Li J, Varma DS, et al. Dietary balance Index-07 and the risk of Anemia in middle aged and elderly people in Southwest 
China: a cross sectional study. Nutrients. 2018;10(2):1-12. https://doi.org/1 0.3390/nu10020162.

13. He YN, Fang YH, Xia J. Update of the Chinese die balance index: DBI-16. Acta Nutrimenta Sinica. 2018;40(06):526-30.

14. Gilham K, Gu Q, Dummer TJB, Spinelli JJ, Murphy RA. Diet Quality and Neighborhood Environment in the Atlantic Partnership for Tomorrow's Health Project. Nutrients. 2020;12(10). https://doi.org/10.3390/nu12103217.

15. Motteli S, Siegrist M, Keller C. Women's social eating environment and its associations with dietary behavior and weight management. Appetite. 2017; 110:86-93. https://doi.org/10.1016/j.appet.2016.12.014.

16. Heaney C, Isreal B. Social relationship and social support. San Francisco: Jossey-Bass; 2008.

17. Southwick SM, Sippel L, Krystal J, Charney D, Mayes L, Pietrzak R. Why are some individuals more resilient than others: the role of social support. World Psychiatry. 2016;15(1):77-9. https://doi.org/10.1002/wps.20282.

18. Dour HJ, Wiley JF, Roy-Byrne P, Stein MB, Sullivan G, Sherbourne CD, et al. Perceived social support mediates anxiety and depressive symptom changes following primary care intervention. Depress Anxiety. 2014;31(5): 436-42. https://doi.org/10.1002/da.22216.

19. Tamers SL, Beresford SA, Cheadle AD, Zheng Y, Bishop SK, Thompson B. The association between worksite social support, diet, physical activity and body mass index. Prev Med. 2011;53(1-2):53-6. https://doi.org/10.1016/j.ypmed.2011.04.012.

20. Lemacks $\mathrm{JL}$, Greer T. Perceived family social support for healthy eating is related to healthy dietary patterns for native Americans: a cross-sectional examination. Fam Community Health. 2020;43(1):26-34. https://doi.org/10.1 097/FCH.0000000000000249.

21. Pieroth R, Rigassio Radler D, Guenther PM, Brewster PJ, Marcus A. The relationship between social support and diet quality in middle-aged and older adults in the United States. J Acad Nutr Diet. 2017;117(8):1272-8. https://doi.org/10.1016/j.jand.2017.03.018.

22. Anderson Steeves E, Jones-Smith J, Hopkins L, Gittelsohn J. Perceived social support from friends and parents for eating behavior and diet quality among low-income, urban, minority youth. J Nutr Educ Behav. 2016;48(5): 304-10 e301. https://doi.org/10.1016/j.jneb.2015.12.014

23. Geller K, Harmon B, Burse N, Strayhorn S. Church-based social Support's impact on African-Americans' physical activity and diet varies by support type and source. J Relig Health. 2019;58(3):977-91. https://doi.org/10.1007/ s10943-018-0576-4.

24. Stanton CA, Green SL, Fries EA. Diet-specific social support among rural adolescents. J Nutr Educ Behav. 2007;39(4):214-8. https://doi.org/10.1016/j. jneb.2006.10.001.

25. Nicklett EJ, Semba RD, Simonsick EM, Szanton S, Bandeen-Roche K, Ferrucci L, et al. Diet quality and social support: factors associated with serum carotenoid concentrations among older disabled women (the Women's health and aging study). J Nutr Health Aging. 2012;16(6):511-8. https://doi org/10.1007/s12603-012-0031-2.

26. Statics CNBo. Data of the Sixth National Population Census. 2012

27. Wang Z, Gordon-Larsen P, Siega-Riz AM, Cai J, Wang H, Adair LS, et al. Sociodemographic disparity in the diet quality transition among Chinese adults from 1991 to 2011. Eur J Clin Nutr. 2017;71(4):486-93. https://doi. org/10.1038/ejcn.2016.179.

28. Li Y, Zhao L, Yu D, Wang Z, Ding G. Metabolic syndrome prevalence and its risk factors among adults in China: a nationally representative crosssectional study. PLoS One. 2018;13(6):e0199293. https://doi.org/10.1371/ journal.pone.0199293.

29. Xu PP, Yang TT, Xu J, Li L, Cao W, Gan Q, et al. Dairy consumption and associations with nutritional status of Chinese children and adolescents. Biomed Environ Sci. 2019;32(6):393-405. https://doi.org/10.3967/bes2019.054.

30. Yang Y. The China food composition table. Beijing: Peking University Medical Press; 2018

31. He Y, Fang Y, Xia J. Update of the Chinese diet balance index: DBI_16. Acta Nutrimenta Sinica. 2018:40(6):526-30.

32. Zhou W, Jin C, Li F, Wang L, Chen W, Xie Z. Influential factors of inpatient care among residents in Shanghai. Zhong nan da xue xue bao Yi xue ban. 2017;:42(12):1432-8.

33. Yu Y, Liu J, Yang Y. Malnutrition and obesity among preschool aged children of 15 native ethnic minority groups in Yunnan Province. Maternal Child Health Care China. 2013;28(22):3636-40.

34. Shi Z, Ganji V. Dietary patterns and cardiovascular disease risk among Chinese adults: a prospective cohort study. Eur J Clin Nutr. 2020;74(12): 1725-35. https://doi.org/10.1038/s41430-020-0668-6.
35. Sun Q, Ma JS, Wang H, Xu SH, Zhao JK, Gao Q, et al. Associations between dietary patterns and 10-year cardiovascular disease risk score levels among Chinese coal miners--a cross-sectional study. BMC Public Health. 2019;19(1): 1704. https://doi.org/10.1186/s12889-019-8070-9.

36. Dong Y, Jan C, Ma Y, Dong B, Zou Z, Yang Y, et al. Economic development and the nutritional status of Chinese school-aged children and adolescents from 1995 to 2014: an analysis of five successive national surveys. Lancet Diabetes Endocrinol. 2019;7(4):288-99. https://doi.org/10.1016/S2213-8587(1 9)30075-0.

37. Zhao J, Liu Z, Tang Q, Min X, Zhang Q, Cai T. Analysis on dietary intake and nutritional status of nu ethnic minority residents in Gongshan. J Kunming Med Univ. 2019;40(6):66-70.

38. Zhao J, Min X, Tang Q, Zhang Q, Liu Z, Cai T. Prevalence and influencing factors of chronic diseases among nu residents aged 15 years and above in Yunnan province, 2016. Chin J Public Health. 2018:34(8):1158-62.

39. Zang J, Yu H, Zhu Z, Lu Y, Liu C, Yao C, et al. Does the dietary pattern of Shanghai residents change across seasons and area of residence: assessing dietary quality using the Chinese diet balance index (DBI). Nutrients. 2017; 9(3):1-18. https://doi.org/10.3390/nu9030251.

40. Xu X, Hall J, Byles J, Shi Z. Assessing dietary quality of older Chinese people using the Chinese diet balance index (DBI). PLoS One. 2015;10(3):e0121618. https://doi.org/10.1371/journal.pone.0121618.

41. Thoits PA. Mechanisms linking social ties and support to physical and mental health. J Health Soc Behav. 2011;52(2):145-61. https://doi.org/10.11 77/0022146510395592.

42. Aggarwal B, Liao M, Allegrante JP, Mosca L. Low social support level is associated with non-adherence to diet at 1 year in the family intervention trial for heart health (FIT heart). J Nutr Educ Behav. 2010;42(6):380-8. https:// doi.org/10.1016/j.jneb.2009.08.006.

43. Draper CE, Grobler L, Micklesfield LK, Norris SA. Impact of social norms and social support on diet, physical activity and sedentary behaviour of adolescents: a scoping review. Child Care Health Dev. 2015;41(5):654-67. https://doi.org/10.1111/cch.12241.

44. Gao C, Xu J, Liu Y, Yang Y. Nutrition policy and healthy China 2030 building. Eur J Clin Nutr. 2021;75(2):238-46. https://doi.org/10.1038/s41430-020-007656.

45. Wang S, Yang $Y$, Hu R, Long H, Wang N, Wang Q, et al. Trends and Associated Factors of Dietary Knowledge among Chinese Older Residents: Results from the China Health and Nutrition Survey 2004-2015. Int J Environ Res Public Health. 2020;17(21). https://doi.org/10.3390/ijerph17218029.

\section{Publisher's Note}

Springer Nature remains neutral with regard to jurisdictional claims in published maps and institutional affiliations.

Ready to submit your research? Choose BMC and benefit from:

- fast, convenient online submission

- thorough peer review by experienced researchers in your field

- rapid publication on acceptance

- support for research data, including large and complex data types

- gold Open Access which fosters wider collaboration and increased citations

- maximum visibility for your research: over $100 \mathrm{M}$ website views per year

At $\mathrm{BMC}$, research is always in progress.

Learn more biomedcentral.com/submission 